\title{
Seasonal activity pattern of Swamp deer (Rucervus duvaucelii duvaucelii) in Dudhwa National Park, Uttar Pradesh, India
}

\author{
Kaleem Ahmed* and Jamal A. Khan \\ Aligarh Muslim University, Aligarh- 202002 (U.P.) INDIA \\ *Corresponding author. E-mail: kaleemdar@gmail.com \\ Received: March 21, 2014; Revised received: May 22, 2014; Accepted: May 30, 2014
}

Conservation Ecology Research Group, Conservation Monitoring Centre, Department of Wildlife Sciences,

\begin{abstract}
The data on activity pattern and time budget of Swamp deer (Rucervus duvauceli duvauceli) were collected through instantaneous scan sampling from Dudhwa National Park, Uttar Pradesh, India Diurnal activity pattern of Swamp deer showed marked reduction in resting in winter as compared to summer. In winter resting in adult males showed polymodal pattern with peaks occurring at different hours of the day and continued throughout the day without any break. Feeding of adult females in winter and summer seasons showed a polymodal pattern with peaks occurring at different hours of the day without break. In yearling males feeding and resting was observed to occur throughout the day during winter season with peaks occurring between 11:00 to 12:00 hours. Yearling females showed continuous feeding throughout the day with peaks in different times in both the seasons. The seasonal distribution of activity patterns of the fawns showed that feeding was slightly more in summer as compared to winter. In time budget, of the expenditure on different activities, resting accounted for $63.77 \%$ and feeding $24.70 \%$. In both the seasons resting was the major portion of their activity. Analysis showed that in all age and sex categories of Swamp deer in the Dudhwa NP, resting dominated on all other activities. The observation on endangered Swamp deer indicates synchronization in activity only in the feeding in the morning and evening hours and resting throughout the day.
\end{abstract}

Key words: Activity pattern, Swamp deer, Dudhwa, Seasonal, Time budget, Terai

\section{INTRODUCTION}

The most obvious factors governing activity patterns in deer are determined by the animal's response to the environmental factors, however, it depends upon the level of perceptibility or tolerance of species towards these factors (Martin, 1977). Deer allocate their time and use available habitats to satisfy basic requirements for food, rumination, movement, social interaction and rest. The resulting time budget and habitat use pattern may vary with age, sex, time of day, season and weather conditions. Estimates of an animal's resource needs through the annual cycle require an understanding of how these factors affect patterns of activity and habitat use. Single estimates and short-term observations of deer behavior fail to convey the dynamic nature of these patterns (Beier and McCullough, 1990).

Information on activity pattern of the animals also helps in understanding foraging and survival strategies in their habitat. These combined with energetic costs of various activities can provide daily, seasonal and annual energy expenditure estimates for each species. Activity pattern and time budget are expected to differ according to the age and sex of the animal. Abiotic factors are also considered to have great influence on these. The Swamp deer (Rucervus duvaucelii duvaucelii) is highly endangered deer species listed in
Schedule - I of the Indian Wildlife Protection Act (1972) and Appendix -I of the Convention on International Trade of Endangered Species (CITES). Despite its legal status, the distribution range of swamp deer has been reduced considerably due to habitat destruction and hunting (Ahmed and Khan, 2008). Keeping the above factors in mind a study was conducted in the Dudhwa National Park (Dudhwa NP) to know the seasonal activity patterns and time budget of different age and sex classes of the Swamp deer.

\section{MATERIALS AND METHODS}

The Dudhwa NP lies between $28^{\circ} 18^{\prime} \mathrm{N}$ and $28^{\circ} 42^{\prime} \mathrm{N}$ latitudes and $80^{\circ} 28^{\prime} \mathrm{E}$ and $80^{\circ} 57^{\prime} \mathrm{E}$ longitudes with a total area of $490.29 \mathrm{~km}^{2}$ and represents one of the few remaining examples of a highly diverse and productive terai ecosystem. The vegetation of the Dudhwa NP is chiefly moist deciduous forest dominated by Sal (Shorea robusta) (Ahmed, 2007) Typical of terai, these forests are interspersed with tracts of low lying grasslands which tend to get flooded during the monsoons. These terai grasslands are prominent characteristics of the Dudhwa NP. The grasslands cover about $19 \%$ of the Dudhwa NP and can broadly be classified into two types - wet low lying areas which are dominated by tall grass species such as Schlerostachya fusca, Phragmites karka, Arundo donax and Saccharum spontaneum, and the drier high 


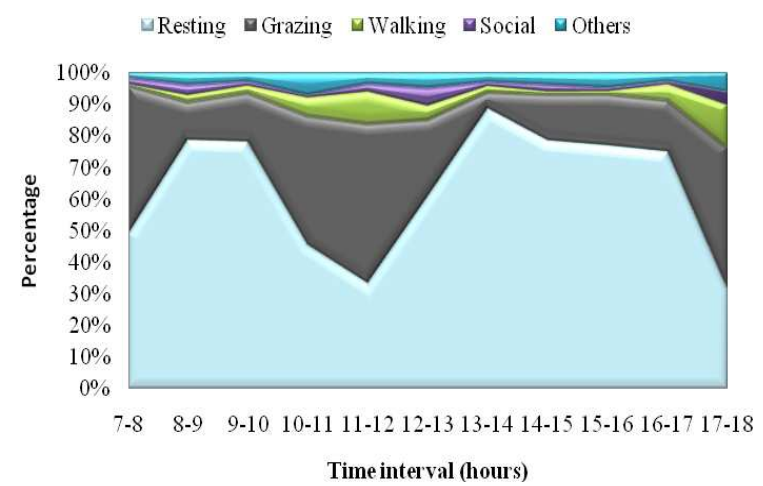

Fig. 1. Winter activity pattern of Swamp deer in DNP.

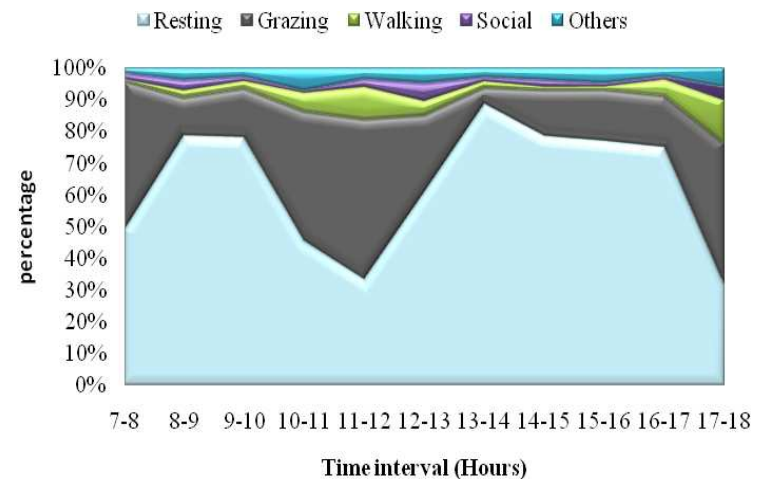

Fig. 2. Summer activity patteren of Swamp deer in DNP.

$\square$ Resting $\square$ Grazing $\square$ Walking $\square$ social $\square$ Others

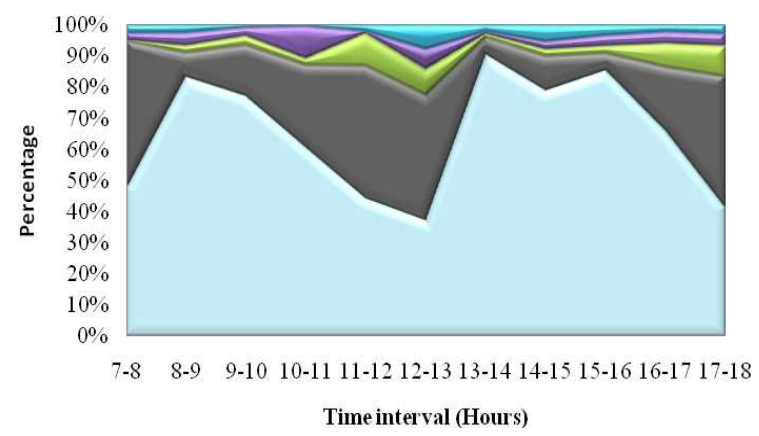

Fig. 3. Diurnal activity pattern of Adult male Swamp deer in winter in DNP.

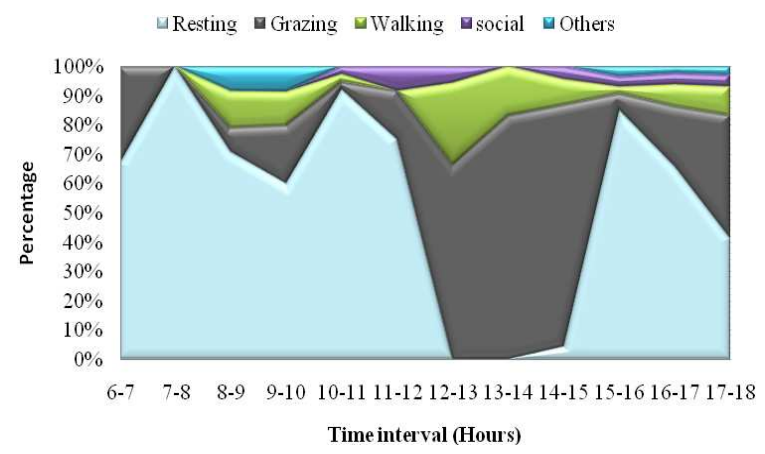

Fig. 4. Diurnal activity pattern of Adult male Swamp deer in summer in DNP.

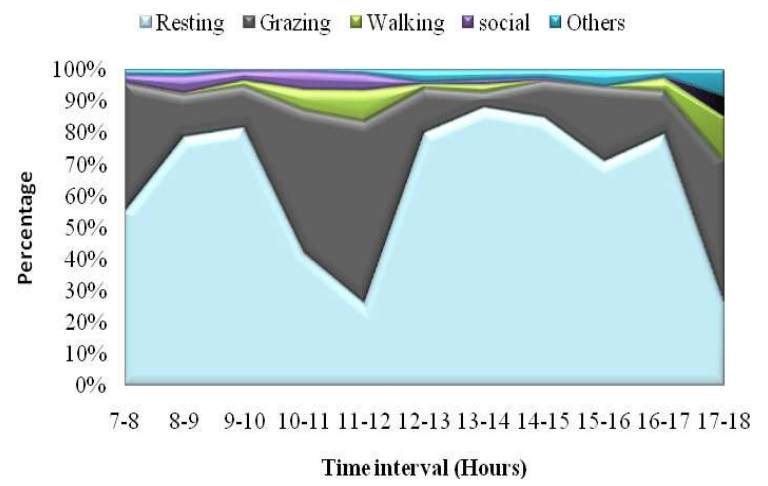

Fig. 5. Diurnal activity pattern of adult female Swamp deer in winter in DNP.

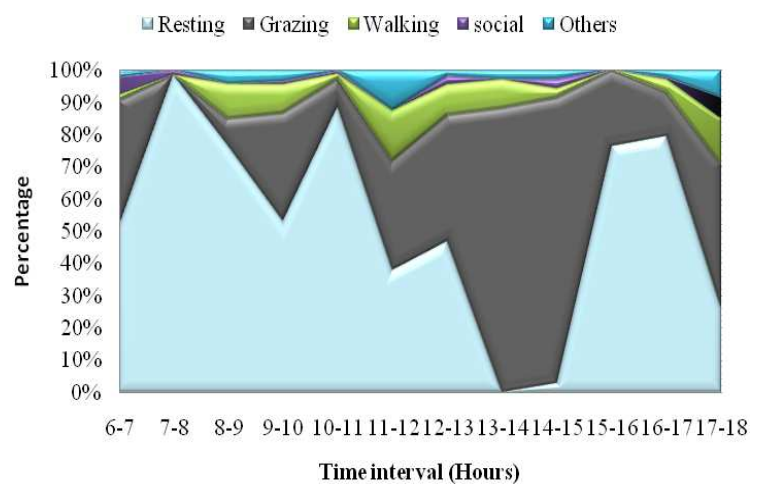

Fig. 6. Diurnal activity pattern of adult female Swamp deer in summer in DNP.

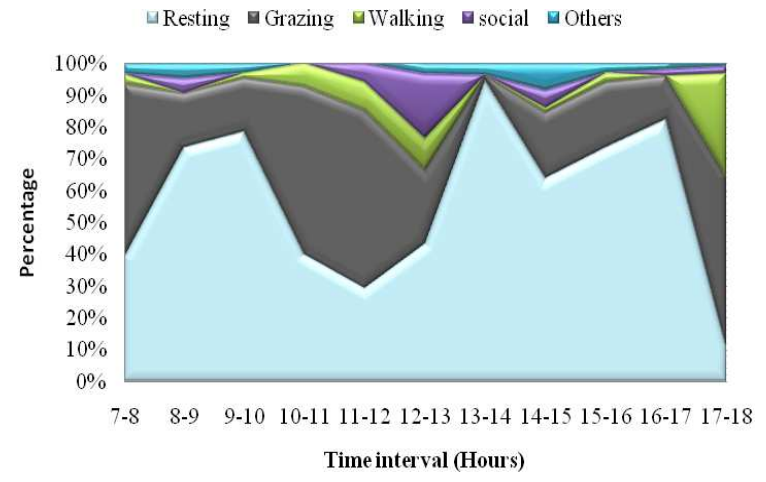

Fig. 7. Diurnal activity pattern of yearling male Swamp deer in winter in DNP.

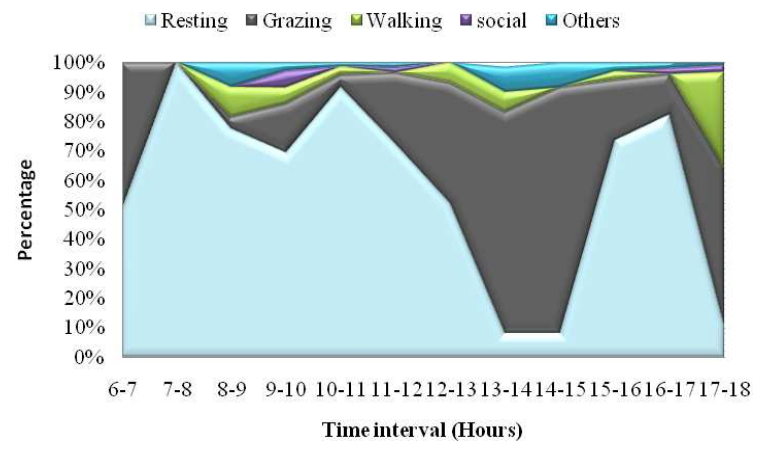

Fig. 8. Diurnal activity pattern of yearling male Swamp deer in summer in DNP. 


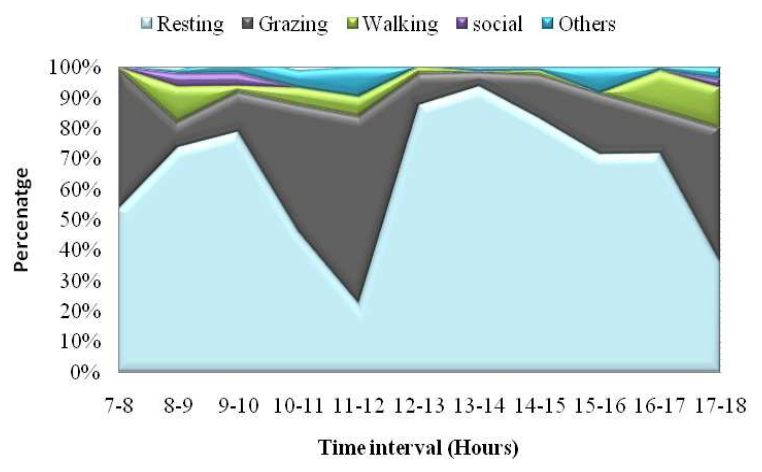

Fig. 9. Diurnal activity pattern of yearling female Swamp deer in winter in DNP.

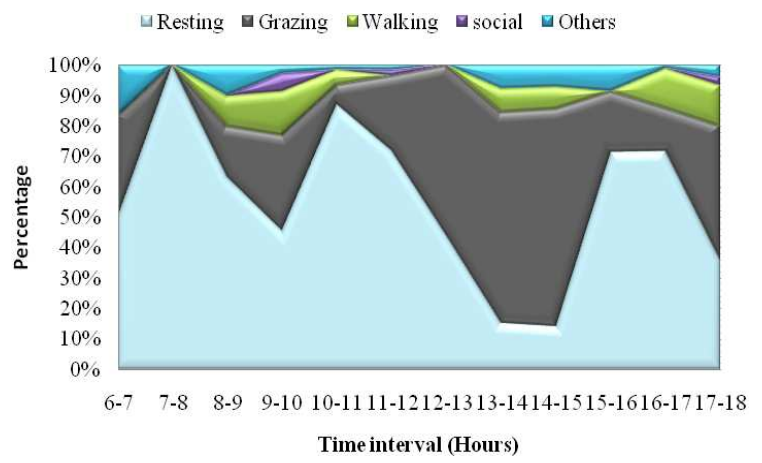

Fig. 10. Diurnal activity pattern of yearling female Swamp deer in summer in DNP.

grounds which are dominated by grasses like Imperata cylindrica, Desmostachya bipinnata, Erianthus munja, Cymbopogon martini (Sankaran, 1990; Kumar et al., 2001; Ahmed, 2007; Ahmed and Khan, 2008). Majority of the areas are upland grassland and form the major habitats of the swamp deer, chital (Axix axis), hog deer (Axis porcinus) and greater one horned rhinoceros (Rhinoceros unicornis). The temperature ranges from $8^{0} \mathrm{C}$ in winter to $45^{\circ} \mathrm{C}$ in summer. The annual climate cycle of the Dudhwa NP includes three seasons: Summer (mid March to mid June) monsoon (mid June to mid October) and winter (mid October to mid March (Ahmed, 2007).

Data pertaining to diurnal activity patterns and time budget were collected through instantaneous scan sampling (Altman, 1974) from December 2005 to June 2006 in the Dudhwa NP. The observations were made between 6.00 to 18.00 hours during summer and between 7.00 to 18.00 hours during winter. During winter the duration of observations was shortened due to extensive fog in the grasslands which restricted the visibility. The animals were observed in groups and the observations were recorded at every 5 minutes interval with an intensity of twelve sampling occasions per hour. The observations were made mostly from machans (hides), from elephant back and on foot keeping in mind the animals do not get disturbed by the observer's presence. Whenever the animals were found to be disturbed, the sampling was terminated and was restarted after the animals settled.

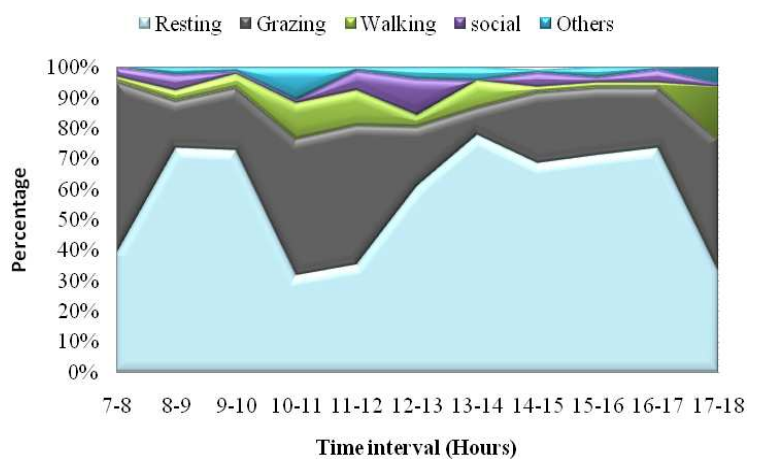

Fig. 11. Diurnal activity pattern of fawn in winter in DNP.

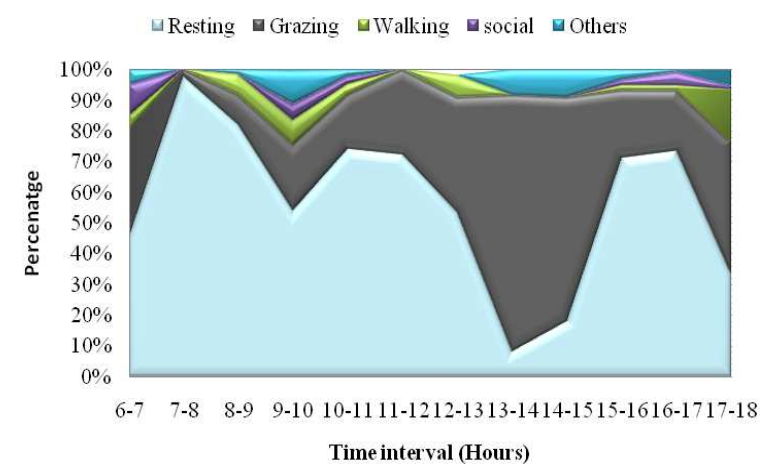

Fig. 12. Diurnal activity pattern of fawn in summer in DNP.

Observations was initiated with the sighting of the herd and lasted till the sunlight favored the visibility or the animal left the location.

The animals in each group were classified into different age and sex categories - adults, sub-adults, yearlings and fawn (Martin, 1977; Ahmed, 2007; Ahmed and Khan, 2008). Activities of the animals were classified as:

- Feeding: Feeding on different plant species.

- Walking: Walking at a steady pace or movements from one location to another while feeding or movements from one place to another after resting.

- Resting: The animal was considered to be resting while standing still or lying with intermittent ruminating.

- Social behavior: Licking on individual by other member of a group, nursing of fawn and playing was included in social behavior.

- Others: Alertness, aggressiveness, urination, defecation, vocalization and rubbing were included in this class.

Analysis was been done for different age and sex categories and for different seasons. The percentage frequency of occurrence of each activity was estimated from the percentage of samples in which a given activity was recorded. The frequency of an activity refers to the number of occurrences of a particular activity during the observed period.

Percentage frequency of activity $i=\frac{\text { Number of occurrence of } i^{\text {th }} \text { activity }}{\text { Total occurrence of all activities }}$ 


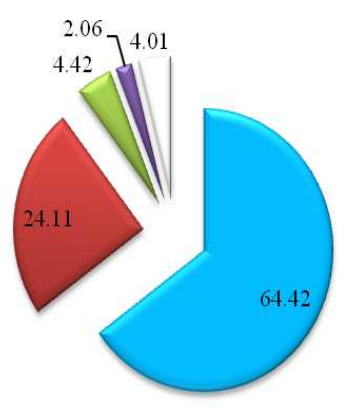

$\square$ Resting $\square$ Grazing $\square$ Walking $\square$ Social $\sqcup$ Others

Fig. 13. Annual activity budget (\%) of Swamp deer in DNP.

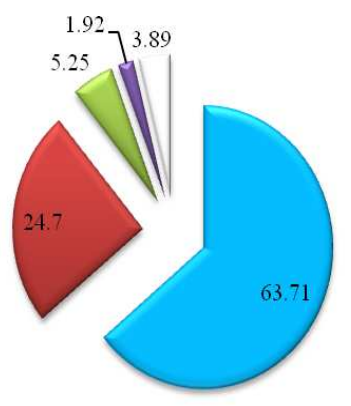

$\square$ Resting $\square$ Grazing $\square$ Walking $\square$ Social $\omega$ Others

Fig. 14. Activity budget (\%) of Swamp deer in winter in DNP.

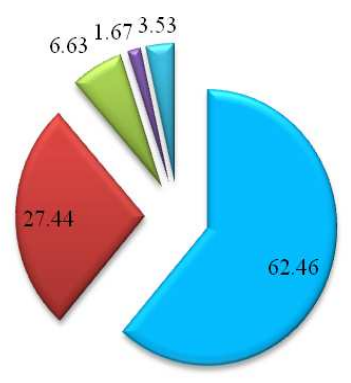

$\square$ Resting $\square$ Grazing $\square$ Walking $\square$ Social $\square$ Others

Fig. 15. Activity budget (\%) of Swamp deer in summer in DNP.

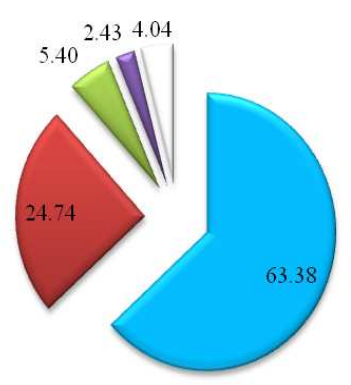

$\square$ Resting $\square$ Grazing $\square$ Walking $\square$ Social $\omega$ Others

Fig. 16. Annual activity budget (\%) of adult male Swamp deer in DNP.

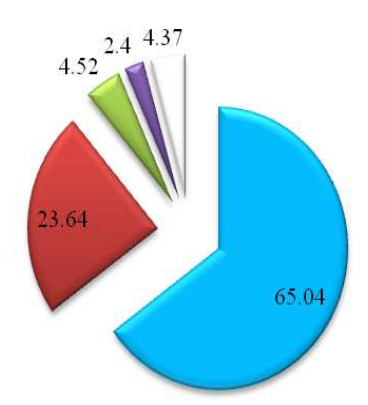

$\square$ Resting $\square$ Grazing $\square$ Walking $\square$ Social $\omega$ Others

Fig. 17. Activity budget (\%) of adult male Swamp deer in winter in DNP.

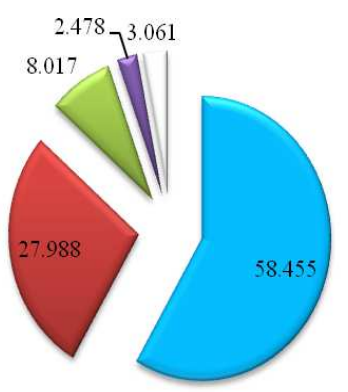

$\square$ Resting $\square$ Grazing $\square$ Walking $\square$ Social $\omega$ Others

Fig. 18. Activity budget (\%) of adult male Swamp deer in summer in DNP.

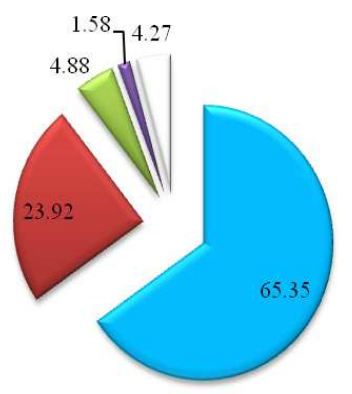

$\square$ Resting $\square$ Grazing $\square$ Walking $\square$ Social $\sqcup$ Others

Fig. 19. Annual activity budget (\%) of adult female Swamp deer in $D N P$.

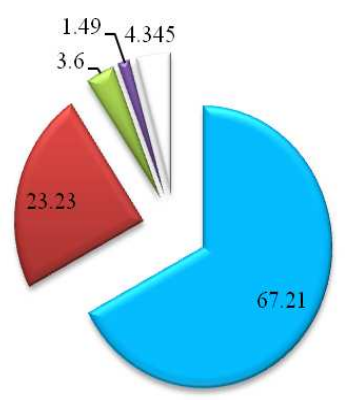

$\square$ Resting $\square$ Grazing $\square$ Walking $\square$ Social $\sqcup$ Others

Fig. 20. Activity budget (\%) of adult female Swamp deer in winter in DNP. 
The number of scans was converted into hours by considering 12 scan hours. The hours of observation were more for adult females and less for other age and sex categories due to the higher percentage of adult female and lower percentage of other categories.

Chi Squared test $\left(\mathrm{c}^{2}\right)$ was carried out to find out the difference in frequency distribution of different activities in the time budget between different age and sex categories and between seasons $(2 \times 5$ contingency table). Time budget for each activity by different age and sex categories was also subjected to $c^{2}$ test.

\section{RESULTS}

Seasonal variation in activity pattern: Diurnal activity pattern of Swamp deer showed marked reduction in resting in winter as compared to summer. Feeding activity prolonged throughout the day without any interruption in both the seasons. The occurrence of feeding in winter was high between 11:00 to 12:00 hours and in summer it was high between 13:00 to 14:00 hours. Walking and social behavior followed almost similar pattern in both the seasons (Figs. 1 and 2).

Activity patterns of different age and sex categories Adult males: In winter, adult males showed resting in polymodal pattern with peaks occurring at different hours of the day and continued throughout the day without any break. In contrast a clear break up in resting was observed from 12:00 to 14:00 hours during summer season. In winter-feeding was peak in 12:00 to 13:00 hours when about $60 \%$ of the animal in a group was active. In summer feeding activity reached highest from 12:00 to 14:00 hours when almost all animals were seen to be active. The duration of walking was highest in summer as compared to winter. Social activities in winter continued through out the day, but in summer it was broken down when feeding seemed to be priority (Figs. 3 and 4)

Adult females: Feeding of adult females in winter and summer seasons showed a polymodal pattern with peaks occurring at different hours of the day without break. However, feeding in winter season peaks during 11:00 to 12:00 hours and in summer it peaks during 13:00 to 14:00 hours. Resting was higher in winter season as compared to summer. In winter resting continued throughout the day, but a clear breakup was observed in summer during 13:00 to 14:00 hours. Walking in summer continued almost throughout the day, considerable decrease in walking was observed in winter season. Social activities were observed both during resting and feeding (Figs. 5 and 6).

Yearling males: Feeding and resting was observed to occur throughout the day during winter season with peaks of feeding occurring between 11:00 to 12:00 hours. In summer feeding was highest between 13:00 to $15: 00$ hours when about $95 \%$ of animals were active. Social activities were more in winter and peaked with fall in feeding (Figs. 7 and 8).

Yearling females: Feeding continued throughout the day in both the seasons with peaks occurring during afternoon in summer and between 13:00 to 15:00 hours in winter. Walking peaks with peak in feeding in both seasons (Figs. 9 and 10)

Fawns: The seasonal activity patterns of the fawns showed that feeding was slightly more in summer as compared to winter. Social behavior was observed more during morning and evening hours in both seasons (Figs. 11 and 12).

Time budget: In total number of observation made during the two seasons in DNP (taking all age and sex categories together), resting accounted for $63.77 \%$ feeding $24.70 \%$. Percentage of time spent on movement and social activities were $5.25 \%$ and $1.92 \%$, respectively. About $3.89 \%$ of the time was spent for other activities (Fig. 13).

In both the seasons resting was the major portion of the activity (Figs 14 and 15). However, slight variations in time expenditure on feeding were observed between two seasons. The time budget for feeding in summer $(27.71 \%)$ was higher compared to winter $(24.11 \%)$. The difference in the percentage time spent on feeding in different seasons found to be significant $\left(\mathrm{c}^{2}=\right.$ 164.94, $\mathrm{P}<0.001)$. About $64.4 \%$ of the time was spent for resting in winter compared to $62.42 \%$ in summer. Time spend for resting in different seasons was also found to be significant $\left(\mathrm{c}^{2}=571, \mathrm{P}<0.001\right)$. The combined analysis for all age and sex categories irrespective of seasons indicated that only $1.92 \%$ of time was spent in social behavior.

\section{Age and sex categories}

Adult male: Analysis, irrespective of seasons, show that the time spent in resting was higher compared to all other activities (Fig 16). In different seasons percentage time spent on different activities was found to be significantly dependent on season $\left(c^{2}=21.36\right.$, $\mathrm{df}$ $=4, \mathrm{P}=0.01)$. Time spent in feeding was more in summer $(27.98 \%)$ as compared to winter $(23.64 \%)$ and the difference was found to be significant $\left(c^{2}=105.59\right.$, $\mathrm{P}<0.001)$. Walking $(8.01 \%)$ in summer was more as compared to winter $(4.52 \%)$ and the difference was found to be significant $\left(\mathrm{c}^{2}=9.31, \mathrm{P}=0.001\right)$ (Figs. 17 and 18).

Adult females: Time spent on different activities, irrespective of seasons, by adult females showed that resting dominated $(63.38 \%)$ on all other activities (Fig. 19). The analysis of the percentage distribution of time spent in different activities between seasons turned to be significant $\left(c^{2}=30.82, d f=4, P=0.01\right.$. Feeding period was more in summer as compared to winter (Figs. 20 and 21).

Yearling males: The combined (irrespective of seasons) analysis indicates that more time was spent in resting (63.33\%) compared to all other activities (Fig. 22). The time spent for feeding, social and others activities were comparatively more in winter as compared to summer (Figs. 23 and 24)

Yearling female: Analysis, irrespective of seasons, of yearling female Swamp deer revealed that resting was the dominant activity (Fig. 25). The time spent in feeding was significantly higher in summer than winter 


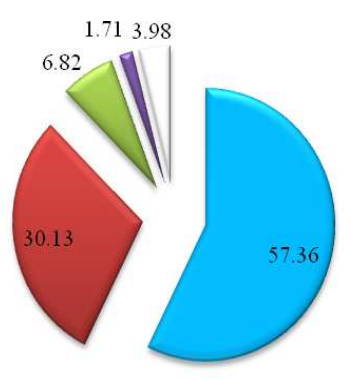

$\square$ Resting $\square$ Grazing $\square$ Walking $\square$ Social $\sqcup$ Others

Fig. 21. Activity budget (\%) of adult female Swamp deer in summer in DNP.

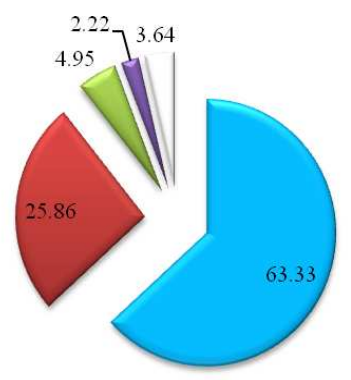

$\square$ Resting $\square$ Grazing $\square$ Walking $\square$ Social $\omega$ Others

Fig. 22. Annual activity budget (\%) of yearling male Swamp deer in DNP.

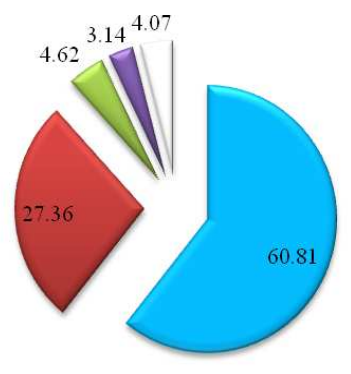

$\square$ Resting $\square$ Grazing $\square$ Walking $\square$ Social $\sqcup$ Others

Fig. 23. Activity budget (\%) of yearling male Swamp deer in winter in DNP.

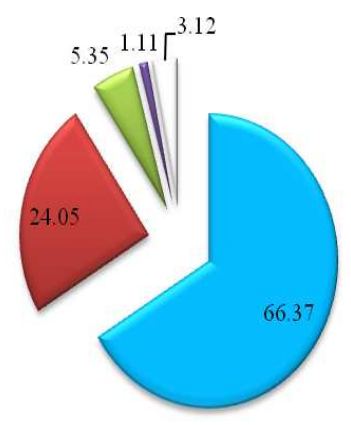

घResting $\square$ Grazing $\square$ Walking $\square$ Social $\sqcup$ Others

Fig. 24. Activity budget (\%) of yearling male Swamp deer in summer in DNP.

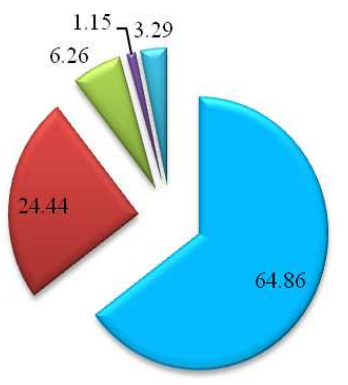

$\square$ Resting $\square$ Grazing $\square$ Walking $\square$ Social $\square$ Others

Fig. 25. Annual activity budget (\%) of yearling female Swamp deer in DNP.

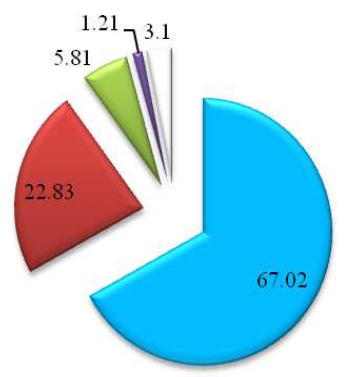

$\square$ Resting $\square$ Grazing $\square$ Walking $\square$ Social $\omega$ Others

Fig. 26. Activity budget (\%) of yearling female Swamp deer in winter in DNP.

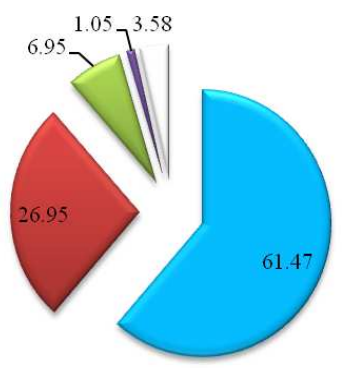

$\llbracket$ Resting $₫$ Grazing $\llbracket$ Walking $₫$ Social $\sqcup$ Others

Fig. 27. Activity budget (\%) of yearling female Swamp deer in summer in DNP.

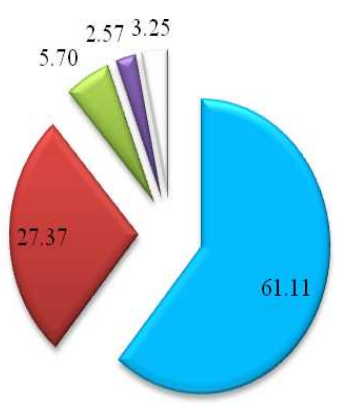

$\square$ Resting $\square$ Grazing $\square$ Walking $\square$ Social $\sqcup$ Others

Fig. 28. Annual activity budget (\%) of fawn Swamp deer in DNP. 


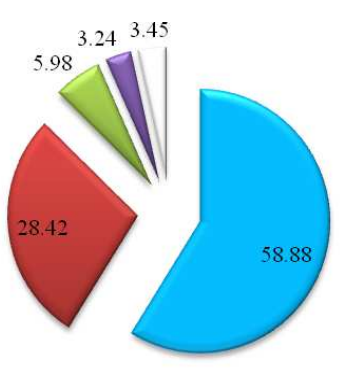

$\square$ Resting $\square$ Grazing $\square$ Walking $\square$ Social $\sqcup$ Others

Fig. 29. Activity budget (\%) of fawn Swamp deer in winter in DNP.

$\left(c^{2}=15.05, P=0.001\right)$ (Figs. 26 and 27).

Fawns: Analysis of overall time budget of Swamp deer fawns showed that more time was spent in resting (Fig. 28). Feeding time was slightly more in winter than summer and difference was found to be significant $\left(c^{2}=28.56, P=0.001\right)$. Social activities were also more in winter than summer $(1.05 \%)$ which was found to be significant $\left(c^{2}=121.48, P=0.001\right)$ (Figs. 29 and $30)$.

\section{DISCUSSION}

Survivorship of animal depends on the time allocated to behaviors governing either the animal's probability of avoiding predation or its energy acquisition rate (Caraco, 1979). Feeding constitutes the major component of all activities in natural population (Rozin, 1976). Bray (1974) and Pankspepp (1974) have described both physical and physiological control of daily and seasonal feeding. An activity profile indicates the time budgeting of animals and suggests species resources utilization in relation to its environment.

Majority of wild ungulates are with many phases of daily activity rhythm in which feeding bouts are interspersed with other activity (Easa, 1998). The present study in the Dudhwa NP indicates that daily activity of Swamp deer is of polyphase where feeding is interspersed with resting and walking. Feeding and walking occurred almost throughout in between resting. Seasonal differences are evident between winter and summer season.

The animals spend two thirds of their time in resting as evident from activity time budget and feeding and walking was other major activity. Significant seasonal differences were also observed in the time spent in feeding. A reduction in feeding time in winter was mostly compensated by an increased resting time. This alternatively suggests that herds may have spent more time in feeding during night. Schaller (1967) observed groups of 20 Swamp deer grazing throughout the night. The summer season had the highest percentage of time spent on feeding and there were marked reduction in resting. The increased summer season feeding time could be attributed to the high-energy

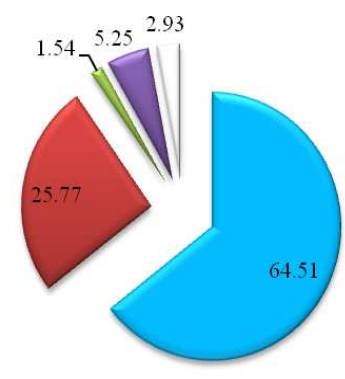

$\square$ Resting $\square$ Grazing $\square$ Social $\square$ Walking $\sqcup$ Others

Fig. 30. Activity budget (\%) of fawn Swamp deer in summer in $D N P$.

requirement of pregnant females in the population. The animals in a herd sometimes grazed intermittently throughout the day. A resting herd was often loose and scattered. The morning activity during summer ceased during 7:00 to 8:00 hours. This study confirms with that of Schaller (1967), who also observed the similar trends in hard ground Swamp deer (Rucervus duvauceli branderi) in Kanha National Park. The activities reached their peaks during afternoon (12:00 to $13: 00$ hours) when about $80 \%$ of animals were active in winter. However, during summer, activity reaches peaks at around 14:00 to 15:00 hours. Herds of Swamp deer maximize their feeding activity around sunset in both the seasons. Martin (1977) also found that daily activity to be maximum around sunsets.

Time budget mediate relation between the environment, individual requirement and resulting sociality (Caraco, 1979; Ahmed and Khan, 2008). Temperature and food density are important environmental factors influencing activity pattern and time budget (Easa, 1998; Ahmed, 2010).

Animals of the same size may differ in their requirement as activity rates are related to physiological conditions of the animals (Crawley, 1983). Though there were differences in the age sex categories of Swamp deer in the study area, a pattern emerges in all categories with the highest feeding in summer and lowest in winter season. Synchronization in activity pattern been reported in a number of ungulates (Shult, 1972; Mitchell, 1977; Leuthold and Leuthold, 1978). The observations in the Dudhwa indicated synchronization in activity only in the feeding in the morning and evening hours and resting through out the day.

\section{ACKNOWLEDGEMENTS}

We are thankful to University Grants Commision for funding this research project and Uttar pradesh Forest Department for giving us permission to work. KA is thanful to their field Assistants Ram Kumar, Radhay Sham, Ram Niwas, Lela Dhar, and Vijay Kumar for their help in conducting the field work. KA is also thankful to late Billy Arjun Singh Passionate discussion with Billy and his knowledge of Dudhwa were of immense help in getting a better insight into the Park. 


\section{REFERENCES}

Ahmed, K. and Khan, J.A. (2008). Status, population structure and conservation of swamp deer (Cervus duvuaceli duvuaceli) in Dudhwa Tiger Reserve. International Journal of Ecology and Environmental Science, 34 (2):75-82.

Ahmed, K. (2007). Ecology and conservation of barasingha (Cervus duvauceli duvauceli) in terai grassland of Uttar Pradesh, India. M.Phil Dissertation. Department of Wildlife Sciences, AMU, Aligarh, pp. 99.

Ahmed, K. (2010). A study on faunal diversity of Dabka and Khulgarh watershed areas of Kumoan Himalayas, Uttarakhand, India. Ph.D. Thesis. Department of Wildlife Sciences, AMU, Aligarh, pp.276.

Altman, J. (1974). Observational study of behaviour: Sampling methods. Behaviour, 49: 227-267.

Beier, P. and McCullough, D.R. (1990). Factors influencing white-tailed deer activity patterns and habitat use. Wildlife Monograph pp,109: 51.

Bray, G.A. (1974). Endocrine factors in the control of food intake. Federation Proceedings, 33: 1140-1145.

Caraco, T. (1979). Time budgeting and group size. A theory. Ecology, 60: 611-617.

Crawley, M.J. (1983). Herbivory. The dynamics of animalplant interactions. Blackwell Scientific Publication, Oxford. pp. 437.

Easa, P.S. (1998). Habitat utilization of animals in Parambikulam Wildlife Sanctuary with special reference to gaur. Kerala Forest Research Institute, Peechi, Kerala, India. Final Report 155, pp. 238.
Kumar, H., Mathur, P.K., Lehmkuhl, J.F., Khati, D.V.S., Rupak, D. and Longwah, W. (2001). Management of forests in India for biological diversity and forests productivity, A New Perspective-Volume VI: Terai Conservation Area (TCA). WII-USDA Forest Service Collaborative Project Report, Wildlife Institute of India, Dehradun. pp. 158.

Leuthold, B.M and Leuthold, W. (1978). Daytime activity patterns of generuk and giraffe in Tsavo National Park, Kenya. East African Wildlife Journal, 16: 231-243.

Martin, C. (1977). Status and ecology of barasingha (Cervus duvauceli branderi) in Kanha National Park (India). Journal of Bombay Natural History Society, 74(1):60132.

Mitchell, A.W. (1977). Preliminary observation on the day time activity patterns of Lesser Kudu in Tsava National Park, Kenya. East African Wildlife Journal, 15:199-206.

Pankspepp, J. (1974). Hypothalamic regulation of energy balance and feeding behaviour. Federation Proceedings, 33: 1150-1165.

Rozin, P. (1976). The selection of food by rats, humans and others animals. Adv. in the Study of Behavior,6: 21-76.

Sankaran, R. (1990). Status of the swamp deer in Dudhwa National Park. Journal of Bombay Natural History Society, 87: 250-259.

Schaller, G.B. (1967). The Deer and the Tiger. A Study of Wildlife in India. The University of Chicago Press, pp. 370.

Shult, M.J. (1972). American bison behavior patterns at Wind Cave National Park. Ph.D. Thesis, Iowa State University, pp. 178. 